\title{
Using OR + Al to predict the optimal production of offshore wind parks: a preliminary study
}

\section{Fischetti, Martina}

Publication date:

2017

\section{Document Version}

Publisher's PDF, also known as Version of record

Link back to DTU Orbit

\section{Citation (APA):}

Fischetti, M. (Author). (2017). Using OR + Al to predict the optimal production of offshore wind parks: a preliminary study. Sound/Visual production (digital), DTU Management Engineering.

\section{General rights}

Copyright and moral rights for the publications made accessible in the public portal are retained by the authors and/or other copyright owners and it is a condition of accessing publications that users recognise and abide by the legal requirements associated with these rights.

- Users may download and print one copy of any publication from the public portal for the purpose of private study or research.

- You may not further distribute the material or use it for any profit-making activity or commercial gain

- You may freely distribute the URL identifying the publication in the public portal

If you believe that this document breaches copyright please contact us providing details, and we will remove access to the work immediately and investigate your claim. 
VATTENFALL

Using OR + Al to predict the optimal production of offshore wind parks: a preliminary study

Martina Fischetti and Marco Fraccaro

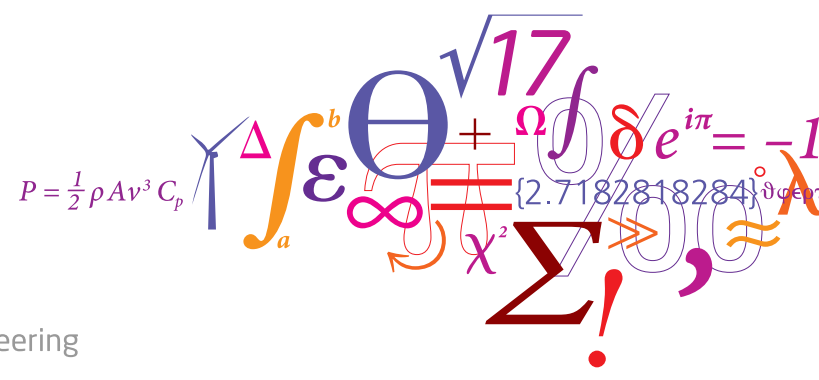

DTU Management Engineering

Department of Management Engineering 


\section{Research question}

Research question: Given a bunch of optimized instances for a given problem, can a machine predict the value of the optimized solution for a new instance? 


\section{Research question}

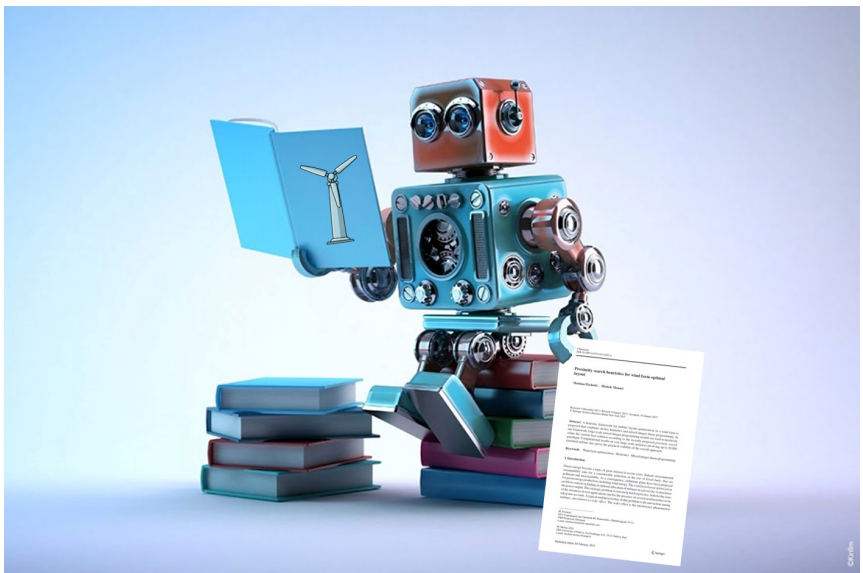

Research question: Given a bunch of optimized wind farm layouts, can a machine predict the production value of the optimized solution for a new site? 


\section{Wind Farm Layout Optimization}

Determine:

a feasible optimal allocation of turbines that maximizes power production. Given:

- a site (offshore)

- characteristics of the turbines to build

- measurements of the wind in the site
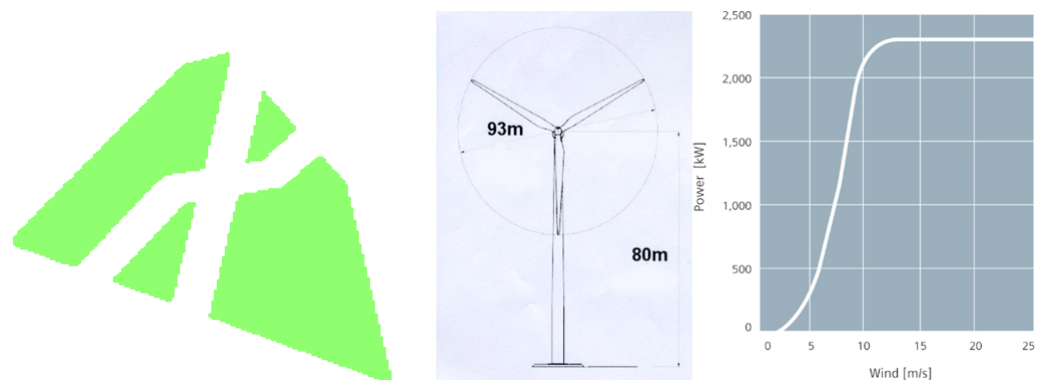


\section{Wind Farm Layout Optimization}

Taking into account:

- proximity constraint

- minimum/maximum number of turbines

- wake effect

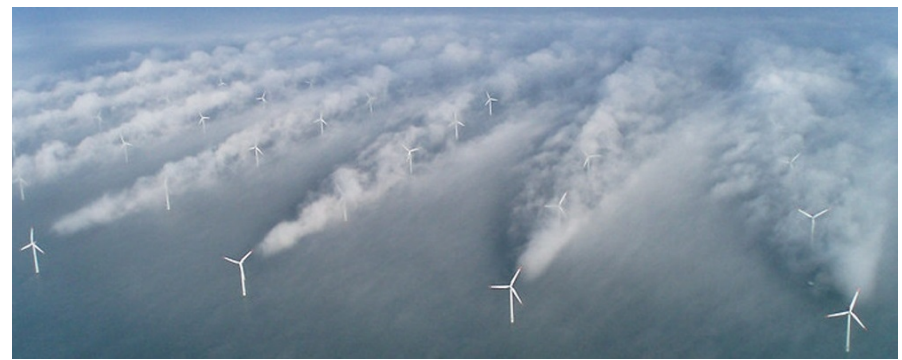




\section{Wind Farm Layout Optimization}

Example of solution for a $3000 \times 3000(\mathrm{~m})$ offshore area. The interference (colors in the background) is the average interference on real-world wind data from Vattenfall

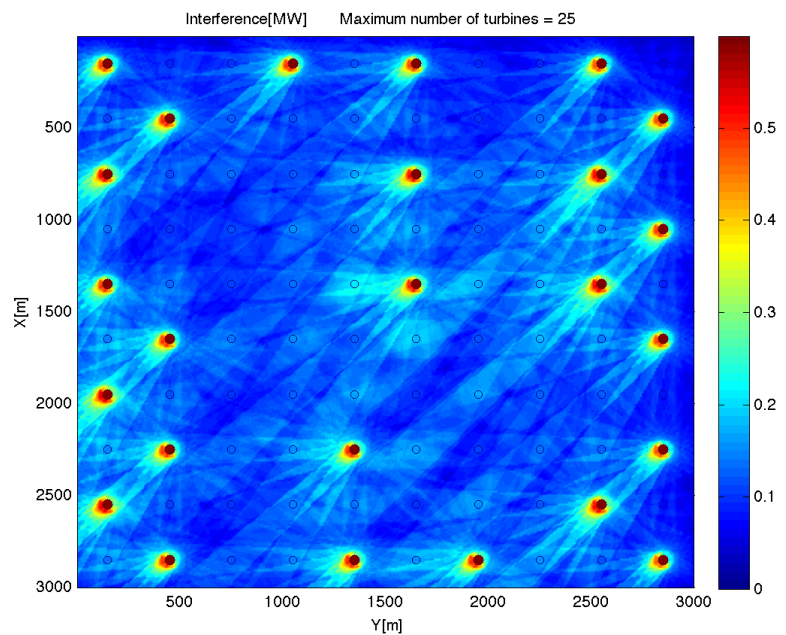




\section{MILP models}

The layout problem can be formulated as a MILP problem.

Variables:

$$
x_{i}= \begin{cases}1 & \text { if a turbine is built at site } i \in V ; \quad(i \in V) \\ 0 & \text { otherwise }\end{cases}
$$

where $\mathrm{V}$ is the set of potential turbine positions.

Let $I_{i, j}$ be the interference (production loss) on $j$ because of $i$ 


\section{MILP models}

The objective function (to be maximized)

$$
\sum_{i \in V} P_{i} x_{i}-\sum_{i \in V}\left(\sum_{j \in V} I_{i j} x_{j}\right) x_{i}
$$

is restated as

$$
\sum_{i \in V}\left(P_{i} x_{i}-w_{i}\right)
$$

where

$$
w_{i}:=\left(\sum_{j \in V} I_{i j} x_{j}\right) x_{i}= \begin{cases}\sum_{j \in V} I_{i j} x_{j} & \text { if } x_{i}=1 \\ 0 & \text { if } x_{i}=0 .\end{cases}
$$

denotes the total interference caused by a turbine in position $i$. 


\section{MILP models}

$$
\begin{array}{ccl}
\max & z=\sum_{i \in V}\left(P_{i} x_{i}-w_{i}\right) & \\
\text { s.t. } & N_{M I N} \leq \sum_{i \in V} x_{i} \leq N_{M A X} & \\
x_{i}+x_{j} \leq 1 & \forall \text { incompatible } i, j \in V, i<j \\
\sum_{j \in V} I_{i j} x_{j} \leq w_{i}+M_{i}\left(1-x_{i}\right) & \forall i \in V \\
x_{i} \in\{0,1\} & \forall i \in V \\
w_{i} \geq 0 & \forall i \in V
\end{array}
$$

where $P_{i}$ and $I_{i j}$ are average values over a large number of wind scenarios, and $M_{i}>>0$ 


\section{Proximity Search}

To solve instances with $10000+$ possible positions

- 1-opt, 2-opt

- Proximity Search on the MILP model

Given an initial (heuristic) solution search for a better solution in the neighbourhood by using the MILP solver as a black box

This algorithm works very well and it is now used inside the company, running the tool overnight

For more info:

- M. Fischetti, M. Monaci, Proximity search heuristics for wind farm optimal layout, Journal of Heuristics 22 (4) (2016) 459-474. 


\section{Machine Learning}

Let us suppose now that the company experts could build a new park wherever they like (i.e. the site is not given) $->$ they should evaluate the potential of a large number of possible sites

Due to the large number of sites, a full optimization $(8 \mathrm{~h}+$ for each site) is infeasible

Research question: Given a bunch of optimized wind farm layouts, can a machine predict the production value of the optimized solution for a new site? 


\section{Building training/test set}

We artificially created different sites by generating sets of possible points on a regular grid ( $10 \mathrm{~m}$ point-to-point distance) inside rectangles of different dimensions (all possible combinations of edge sizes 6000, 7000, 8000, 9000, $10000,11000,12000,13000$ and $14000 \mathrm{~m})$.
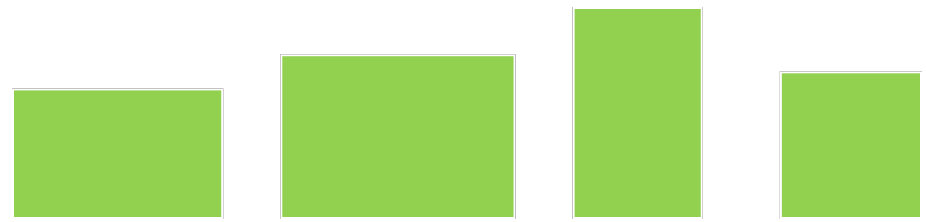


\section{Building training/test set}

- Adwen $8 \mathrm{MW}$, with a rotor diameter of $180 \mathrm{~m}$

- Vestas 8.4 MW, with a rotor diameter of $164 \mathrm{~m}$

- Siemens $7 \mathrm{MW}$, with a rotor diameter of $154 \mathrm{~m}$

- Vestas $8 \mathrm{MW}$, with a rotor diameter of $164 \mathrm{~m}$

- Siemens 3.2 MW, with a rotor diameter of $113 \mathrm{~m}$

- Siemens 2.3 MW, with a rotor diameter of $101 \mathrm{~m}$ 


\section{Building training/test set}

Real-world wind statistics from the real offshore wind parks (Borssele 1 and 2, Borssele 3 and 4, Danish Krigers Flak and Ormonde).

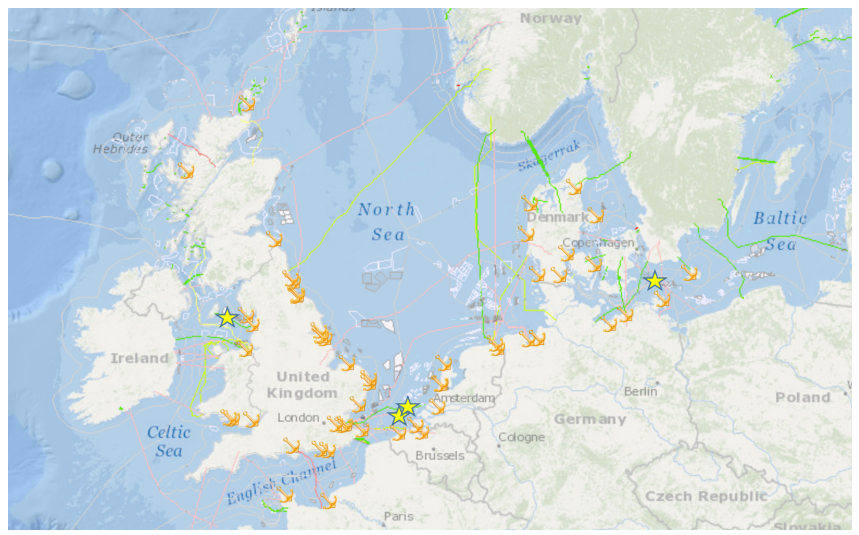

We imposed that a fixed number of 50 turbines needs to be located in the site, minimum distance 5 rotor diameters $\rightarrow$ we obtained about 2000+ instances

14 DTU Management Engineering Using OR + Al to predict the optimal production of offshore wind parks: a 


\section{Building training/test set}

(1) the so-called gross production, i.e., the power production of the optimized solution neglecting the interference factor

2 the optimized layout and its power production 


\section{Building training/test set}

(1) the so-called gross production, i.e., the power production of the optimized solution neglecting the interference factor

$\rightarrow$ this will be used as input information (feature)

2 the optimized layout and its power production

$\rightarrow$ this is what we want to predict 


\section{Building training/test set}

(1) the so-called gross production, i.e., the power production of the optimized solution neglecting the interference factor)

$\rightarrow$ this will be used as input information (feature)

2 the optimized layout and its power production

$\rightarrow$ this is what we want to predict

1) requires short computing time and can be calculated in a pre-processing step.

Optimization for the difficult case 2) was obtained through our MILP-based heuristic [1], with a time limit of 1 hour on a standard PC using IBM ILOG CPLEX 12.6.

[1] M. Fischetti, M. Monaci, Proximity search heuristics for wind farm optimal layout, Journal of Heuristics 22 (4) (2016) 459-474. 


\section{Building training/test set}

Finally, instead of directly estimating the optimized production of a site, we estimate its normalized difference from the gross production, defined as

$$
\text { reduction }=\frac{\text { gross production }- \text { optimized production }}{\text { gross production }}
$$

This is a value between 0 and 1 that can easily be compared between instances with production of different scales. 


\section{Feature selection}

In order for our ML models to capture the wind park problem, it is very important to describe its characteristics in a meaningful way.

Selected features:

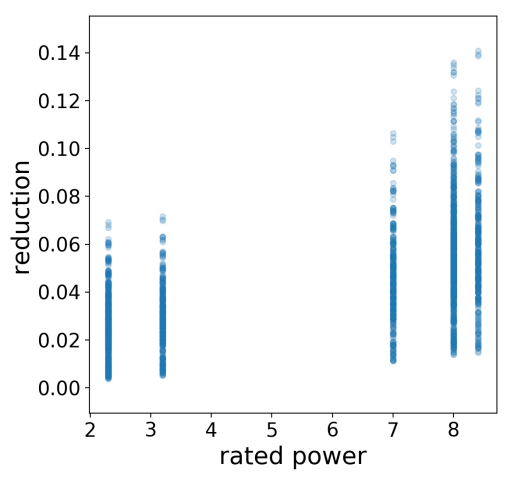

- rated power for the turbine model [MW] 


\section{Feature selection}

In order for our ML models to capture the wind park problem, it is very important to describe its characteristics in a meaningful way.

Selected features:

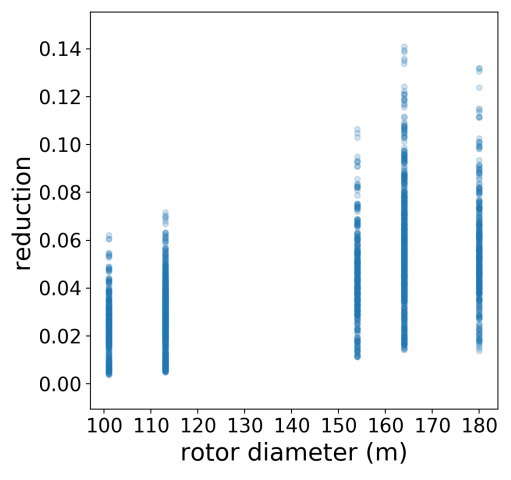

- rated power for the turbine model [MW]

- rotor diameter for the turbine model $[\mathrm{m}]$ 


\section{Feature selection}

In order for our ML models to capture the wind park problem, it is very important to describe its characteristics in a meaningful way.

Selected features:

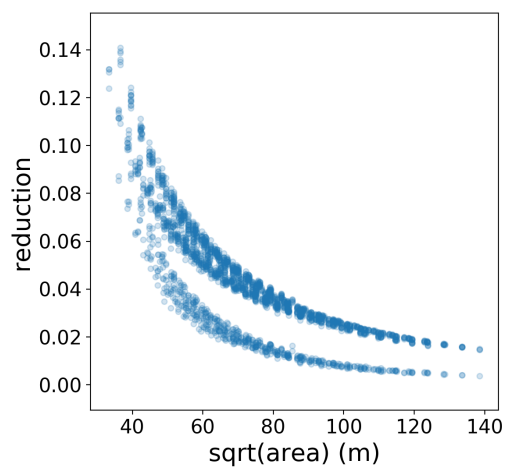

- rated power for the turbine model [MW]

- rotor diameter for the turbine model $[\mathrm{m}]$

- the square root of the area of the site [rotor diameters] 


\section{Feature selection}

In order for our ML models to capture the wind park problem, it is very important to describe its characteristics in a meaningful way.

Selected features:

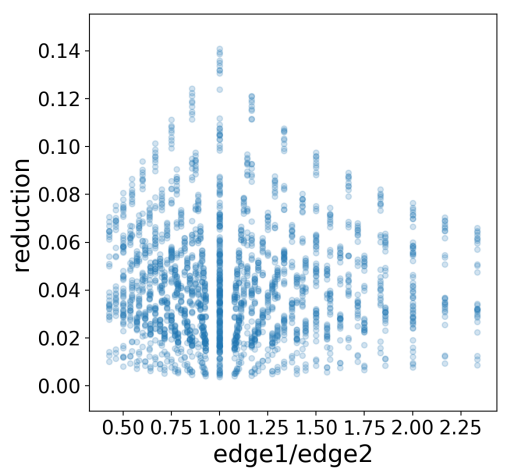

- rated power for the turbine model [MW]

- rotor diameter for the turbine model $[\mathrm{m}]$

- the square root of the area of the site [rotor diameters]

- the ratio between the two edges of the rectangle 


\section{Feature selection}

In order for our ML models to capture the wind park problem, it is very important to describe its characteristics in a meaningful way.

Selected features:

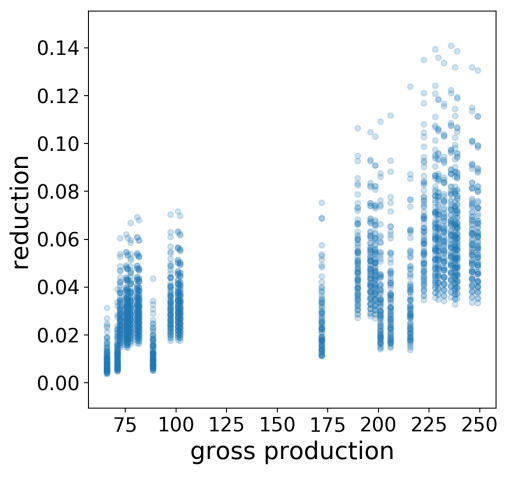

- rated power for the turbine model [MW]

- rotor diameter for the turbine model $[\mathrm{m}]$

- the square root of the area of the site [rotor diameters]

- the ratio between the two edges of the rectangle

- the production without interference [MW] 


\section{Machine Learning}

Two different ML models to estimate the reduction in power production due to the interference:

- Linear Regression

- Neural Networks (NNs)

In addition, we also defined a simple baseline model (Mean Value), that regardless of its input always predicts the mean reduction of the training set. This last model mimics what is normally done by humans, and is used for comparison. 


\section{Machine Learning}

2268 instances

-> training set randomly choosing $60 \%$ of the instances;

-> test set the remaining $40 \%$

$\rightarrow$ hyperparameters of the models are chosen using the scikit-learn ${ }^{1}$ function GridSearchCV (5-fold cross-validated on the training set)

\footnotetext{
${ }^{1}$ a ML library for python
}

19 DTU Management Engineering Using OR + Al to predict the optimal production of offshore wind parks: a 


\section{Results}

What a human would do: reduction mean value

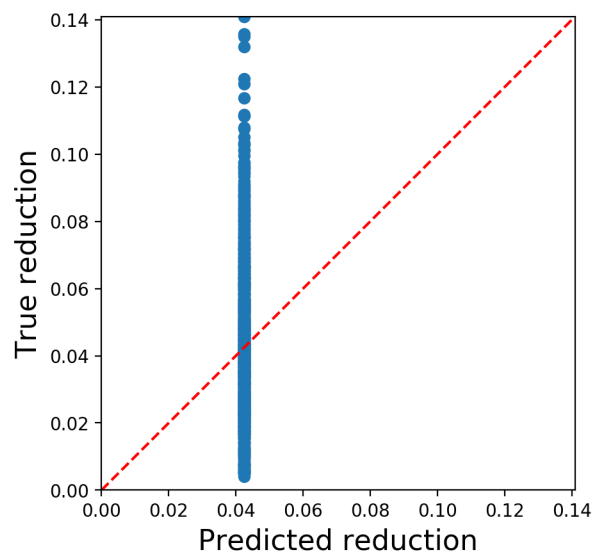

Figure: Mean Value 


\section{Results}

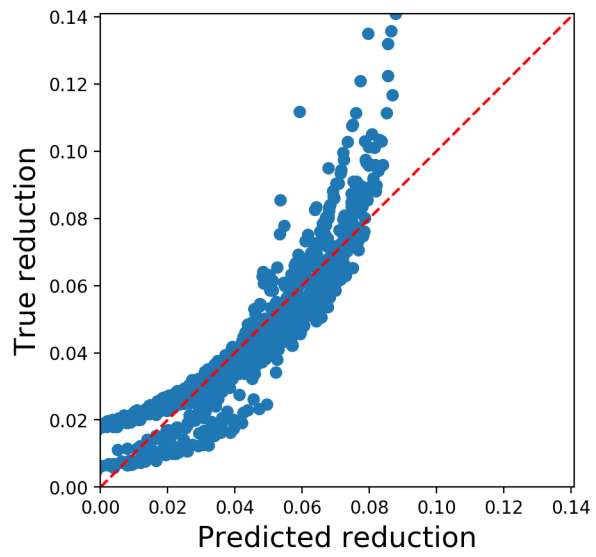

Figure: Linear Regression 


\section{Results}

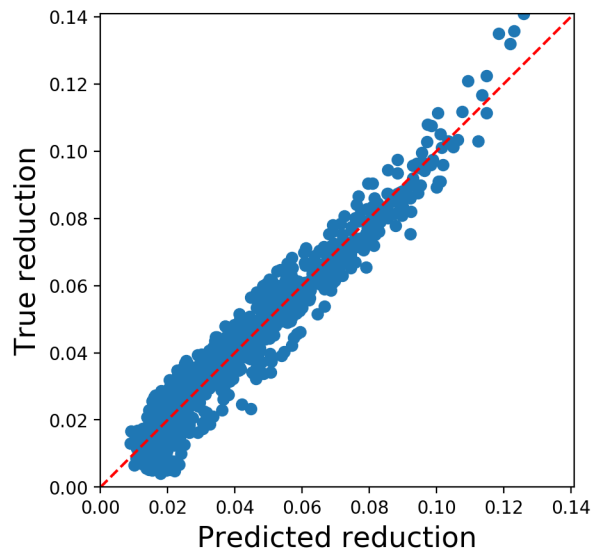

Figure: Neural Network 


\section{Conclusions}

This preliminary work shows

- the relevance of using $M O$ and $M L$ techniques together;

- that ML techniques (NNs in particular), trained on a large number of optimized solutions, could well predict the optimal value of new instances of the same (wind park layout) problem

- that the ML estimate highly outperforms the human estimate (Mean Value model) 


\section{Recent work}

We have further worked on this project.

- we increased the number of instances including additional sites 


\section{Recent work}

We have further worked on this project.

- we increased the number of instances including additional sites

- instead of the gross production we used the production (with wake effect) of a regular layout on a grid (both as feature and as banchmark) 


\section{Recent work}

We have further worked on this project.

- we increased the number of instances including additional sites

- instead of the gross production we used the production (with wake effect) of a regular layout on a grid (both as feature and as banchmark)

- we better defined our training/test set (not randomly selected but depending on the wind in the site) 


\section{Recent work}

We have further worked on this project.

- we increased the number of instances including additional sites

- instead of the gross production we used the production (with wake effect) of a regular layout on a grid (both as feature and as banchmark)

- we better defined our training/test set (not randomly selected but depending on the wind in the site)

- we designed new ML models (i.e. Support Vector Regression) 


\section{Future work}

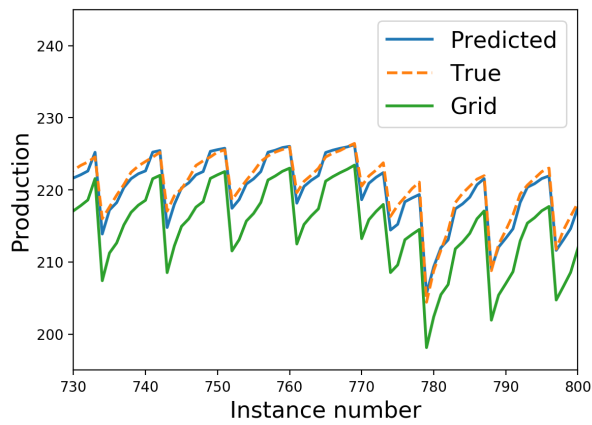

Figure: Support Vector Regression

For more info:

- M. Fischetti, M. Fraccaro, Machine Learning meets Mathematical Optimization to predict the optimal production of offshore wind parks(submitted). 